\title{
Correction to: Digital Business Model Patterns of Big Pharmaceutical Companies - A Cluster Analysis
}

\author{
Cyrine Tangour (1D, Marc Gebauer, Luise Fischer (1D, \\ and Herwig Winkler
}

\section{Correction to: \\ Chapter "Digital Business Model Patterns of Big Pharmaceutical Companies - A Cluster Analysis" \\ in: R. Jallouli et al. (Eds.): Digital Economy, LNBIP 358, https://doi.org/10.1007/978-3-030-30874-2_31}

In the originally published version of this chapter, the name of the fourth author Herwig Winkler was incorrect. The name of the author has been corrected. 